Kassab, O.A., Young B.K., and Laedre, O. 2020. "Implementation of Last Planner ${ }^{\circledR}$ System in an Infrastructure Project." In: Tommelein, I.D. and Daniel, E. (eds.). Proc. $28^{\text {th }}$ Annual Conference of the International Group for Lean Construction (IGLC28), Berkeley, California, USA, doi.org/10.24928/2020/0089, online at iglc.net.

\title{
IMPLEMENTATION OF LAST PLANNER® SYSTEM IN AN INFRASTRUCTURE PROJECT
}

\author{
Omar A. Kassab', Brendan K. Young ${ }^{2}$, and Ola Ladre ${ }^{3}$
}

\begin{abstract}
Since the establishment of the Last Planner ${ }^{\circledR}$ system (LPS) by Ballard and Howell, multiple studies have been conducted to evaluate the implementation of LPS in many construction projects. However, few studies have recorded the implementation process in infrastructure projects. This study investigates the implementation of LPS in an infrastructure project (Minnevika Bridge project), detect the challenges that arise during the implementation, and suggest measures to overcome these challenges. Several data collection methods were used in an action research approach; namely, a single case study, a literature study, non-participant/participant observations, six semi-structured interviews and two surveys.

The study revealed that the project followed the best practice process map for LPS implementation mentioned in the literature. Moreover, the project experienced challenges described in the literature that tend to arise when adopting LPS, similar to those reported from other construction projects (e.g. participants' resistance to the system). The study concludes with suggested measures to overcome these challenges (e.g. sufficient training and openness towards the LPS). Finally, the researchers represent challenges that are not clearly described in the literature (e.g., fear of responsibility when making the commitments).
\end{abstract}

\section{KEYWORDS}

Lean construction, Last Planner System, Action research, Challenges, Infrastructure

\section{INTRODUCTION}

According to the research report conducted by Barbosa et al. (2017), the construction industry lags behind other industries in terms of productivity. This is demonstrated by an annual $1.0 \%$ increase in productivity in the construction industry, compared to $3.6 \%$ for the manufacturing industry over the past 20 years. One of those factors causing productivity increase is the use of Lean manufacturing in the production process. Koskela (1992) aspired to apply Lean manufacturing to the construction industry. Later, Howell and Ballard (1998) claimed that Lean is suitable for dynamic projects, as it is the case in

MSc Candidate, Norwegian University of Science and Technology (NTNU), Trondheim, Norway, +4796877993, omarka@stud.ntnu.no, orcid.org/0000-0002-3768-3592

2 Site Manager, PNC Norge AS, Oslo Norway, +4747713728, brendan.young@pnc-norge.no, orcid.org/0000-0003-2532-8670

3 Associate Professor, Norwegian University of Science and Technology (NTNU), Trondheim, Norway, +4773594739, ola.ladre@ntnu.no, orcid.org/0000-0003-4604-8299 
construction projects. Multiple Lean construction tools have been developed since then (Ansah et al. 2016). The Last Planner ${ }^{\circledR}$ System, which has been developed and invented by Ballard and Howell, is classified as the most advanced tool in Lean construction (Cerveró-Romero et al. 2013). Howell and Ballard (1998) developed LPS to enhance the workflow reliability in projects. Increased workflow reliability leads to a reduction in overall waste (Ballard and Tommelein 2016). As a part of the construction industry in Norway, PNC Norge AS (the company under-study) experienced a need for increased workflow reliability. To improve their internal work practices, they have chosen to introduce the Last Planner ${ }^{\circledR}$ System on one of their projects as a pilot. The project referred to as Minnevika Bridge. LPS can help them in turn to improve their productivity, focus on increasing the customer's value, reduce the non-value adding activities, and as a way to distribute ownership of the project to all levels of the project organisation.

Multiple studies have been conducted to evaluate the implementation of LPS in construction projects around the world, but few studies have recorded the implementation process in infrastructure projects. Therefore, this study fills this gap by examining the following research questions:

1. How is PNC going to implement The Last Planner System (LPS) in Minnevika Bridge project?

2. What are the challenges that arise during the implementation of LPS?

\section{RESEARCH METHOD}

PNC Norge AS forms part of the Joint Venture (JV), AFHP, which is the main contractor for the construction of the Eidsvoll Nord-Langset project. As part of this joint venture, PNC is responsible for the Minnevika Railway Bridge. The bridge is 836 metres long, which will become Norway's longest railway bridge. It is a Design-bid-build contract. The LPS was not used during the design phase, nor was there any interest from the client to participate in the process. PNC is the only user of LPS. However, the JV partner and all the subcontractors were invited to participate in the implementation process.

In action research, the researchers work with the studied organisation to answer practical issues that show up (Järvinen 2007). The presence of two of the authors as employees in the Minnevika Bridge project facilitated the data collection. Multiple methods for data collection were used, namely a literature study, nonparticipant/participant observations, semi-structured interviews and two surveys.

A comprehensive literature review - according to the steps mentioned by Wee and Banister (2016) - was done to find the best possible practice for LPS implementation in construction projects. In special, the literature review investigated challenges faced by eleven case studies of LPS implementation. The researchers attempted to focus more on the challenges that occurred in infrastructure projects, but also considered other construction projects. The challenges faced by these eleven cases were compared to the challenges detected in the Minnevika Bridge project.

The first author carried out - non-participant - observations in an initial training session to record participants' attitudes towards the system. Then the first author carried out - participant - observations in three workshops and in the weekly Production Evaluation and Planning (PEP)-meetings to identify planning practices and detect challenges arising.

Two semi-structured interviews with the LPS Trainers were conducted to examine the LPS implementation in the project, the challenges expected, and measures to tackle these challenges. Four semi-structured interviews were conducted with the LPS Facilitator, a 
Site Manager, a Site Engineer, and the Project Planner. The two first interviews were carried out before the implementation, and the four next interviews were implemented during the implementation.

A first survey - comprised of 15 closed-ended questions and one open-ended question - was answered by 13 respondents from the training session to examine openness towards the LPS, and to record the challenges from the participants' perspective. A second survey - comprised of 22 closed-ended questions and one open-ended question - was answered by eight respondents during Execution Phase (the phase after the Training Phase as will be indicated later in the Results chapter) to examine openness towards the LPS. Moreover, the second survey encompassed a dedicated section, using Likert scale method, to determine critical challenges from the participants' point of view that arose during the Execution Phase.

\section{LITERATURE REVIEW}

\section{Last Planner ${ }^{\circledR}$ System}

Glenn Ballard and Greg Howell were the ones that invented the Last Planner® System in 1992 and took the lead for improving the LPS over the last three decades. Several papers have previously been published by Ballard related to this system, the first of them was published in 1993 and was called Improving EPC Performance (Ballard 1993) at the first Conference of the International Group for Lean Construction (IGLC), where he mentioned the term Last Planner® system. The Last Planner ${ }^{\circledR}$ System is primarily based on all the principles of Lean Construction which always seek for perfection, and excellent performance concerning productivity and this can be realised by the improvement of reliability of planning, which in turn can be done by "taking action in several levels in the planning system" (Ballard and Hamzeh et al. 2007). The main focus of LPS is to reduce the uncertainty and variability in a project's workflow, which has been neglected by the traditional project management and appears to be the primary factor for the low performance of construction projects (Ballard and Howell 2003; Howell and Ballard 1998). The LPS also seeks to improve the predictability of the planned activities on construction sites (Mossman 2014).

The Last Planner ${ }^{\circledR}$ System planning cycle (implementation process) is made up of four different levels; namely, the master schedule level, the phase schedule level, lookahead planning level, and finally the weekly work plan (WWP) level (Ballard et al. 2007a). The master and phase schedules are part of a planning phase called front-end planning, whereas the lookahead planning and the WWP are part of another planning phase called production planning. The process starts with front-end planning. In this phase, the master schedule is carried out, which means setting up the milestones and conducting the Critical Path Method (CPM) in order to recognise the overall project duration and budget. After carrying out the master schedules, comes the more detailed scheduling, the phase schedule, which improves during the lifetime of the project. The participants can modify the Critical Path Method by using collaborative planning, and the reverse phase scheduling (pull technique) (Ballard et al. 2007a). Once the phase schedule ends, the second phase, the production planning phase, begins. In this phase, we start by magnifying the activities from the phase schedule to the more detailed lookahead plan (a process called explosion). The participants plan what they are going to do in the upcoming six weeks (the typical number of planning weeks to have a reliable plan). Any constraints that threaten the workflow should be studied to be removed (referred to as constraints 
analysis). The constraints analysis should be carried out every week, followed by an update to the Lookahead plan. Every participant of the team should identify their responsibilities, make assignments ready (this is called make-ready), and finally analyse the resource management information (Ballard et al. 2007a). Subsequently, the weekly work plan (WWP) can be carried out; this plan is considered as the most detailed plan compared to all the previous plans. Ballard et al. (2007a) mentioned the (WWP) in their research and said that "It directly drives the production process". The quality assignments and reliable promises are then conducted so as to have more reliable plans; as a result, the production unit now is shielded by those quality assignments form the uncertainty in the upstream. Finally, The participants have to analyse reasons for non-completion (RNC) and learn from that for future work; this can be obtained by performing a root cause analysis to identify "the source of the action or event chain in order to learn how repeated failures can be prevented ". Additionally, The participants can utilise some key performance indicators such as the Percent plan complete (PPC) to measure the system performance. The PPC is defined according to Ballard et al. (2007a) as "the number of actual completions divided by the number of assignments for a given week."

Futhermore, Ballard (1994) presented the team workshop in order to develop the LPS process (Lim et al. 2006). Additionally, Ballard et al. (2007b) mentioned that companies utilise two different mechanisms for training their personnel in LPS; some of them learn by doing, while other firms require a certain amount of training (classroom training). The workshops and the training sessions have been applied in many projects, according to the following research papers (Alsehaimi et al. 2014; Lim et al. 2006). Finally, in their publication, Perez and Ghosh (2018) presented the recommended best practice process map for LPS implementation (based on an extensive literature review). This best practice process map was identical to the planning cycle mentioned by Ballard et al. (2007a).

\section{LAST Planner® System IMPLEMENTATION CHALLENGES}

Last Planner ${ }^{\circledR}$ System has multiple advantages, but still, many organisations confront sufficiently significant obstacles when implementing this new system (Hamzeh 2009).

A wide range of literature has already examined and evaluated the Last planner ${ }^{\circledR}$ System's performance in different countries over the last years. Some of them highlighted the success stories of the implementation of the Last Planner® System in several projects, while the other part of the literature indicated the challenges that arose during the execution through complete or partially failed stories of the application of LPS. The researchers have recorded two types of challenges that tended to appear during the implementation. One of them is related to the LPS components and practical use of LPS, called "the practical challenges", while the other type is associated with the transformation process or to the Participants' attitudes and behaviours, referred to as "soft (intangible) challenges" as described by Hamzeh and Bergstrom (2010). In this literature review, the researchers concentrate on both types of challenges, as this research is mainly based on the challenges in general and not limited to a specific type. There are several challenges that appear during the implementation process related to organisational change, and there are many publications from the researchers in the field of change management and Lean construction that included a trial of various organisations to conduct Lean practices. Some of these organisations failed, while the other organisations did not manage to reach the correct form of Lean production, or achieved it to a certain degree (Ballard et al. 2007b; Hamzeh and Bergstrom 2010; Kotter 2012; Liker 2004). Teamwork and continuous improvement are the major components of Lean production. Sadly, many 
organisations fail to work with them, especially in the construction industry, which includes several "self-interested parties" that are not motivated to develop. They do not know each other and do not have the trust between each other (Liker 2004).

In the following tables 1 and 2, the researchers have summarised the most critical challenges faced by the construction industry professionals when implementing LPS in construction projects (using eleven case studies). It is noteworthy of mentioning that this table is presented following the format utilised by Fernandez-Solis et al. (2013).

Table 1: List of case studies

\begin{tabular}{|c|c|c|c|}
\hline Case & Reference & Projects & Project type \\
\hline C1 & Ballard et al. (2007b) & Air Products: Large chemical plant & Industry \\
\hline $\mathrm{C} 2$ & Ballard et al. (2007b) & $\begin{array}{l}\text { Heathrow Terminal } 5 \text { building: civil } \\
\text { phase }\end{array}$ & Commercial \\
\hline C3 & Hamzeh (2009) & Cathedral Hill Hospital project & Health care \\
\hline C4 & Alsehaimi et al. (2014) & $\begin{array}{l}\text { Faculty of business and administration } \\
\text { building }\end{array}$ & Institutional \\
\hline C5 & Alsehaimi et al. (2014) & General classrooms and laboratories & Institutional \\
\hline C6 & Kim et al. (2007) & Seoul subway project & Infrastructure \\
\hline C7 & Kim et al. (2007) & Busan subway project & Infrastructure \\
\hline C8 & Ansell et al. (2007) & 3 miles of carriageway renewal & Infrastructure \\
\hline C9 & Jang et al. (2007) & Seoul Ring Road project & Infrastructure \\
\hline C10 & $\begin{array}{l}\text { Cerveró-Romero et al. } \\
(2013)\end{array}$ & GDL project & Infrastructure \\
\hline C11 & $\begin{array}{l}\text { Cerveró-Romero et al. } \\
(2013)\end{array}$ & Los Cabos project & Infrastructure \\
\hline
\end{tabular}

Table 2: Reported challenges and the corresponding case studies

\begin{tabular}{|c|c|c|}
\hline$T \mathrm{TY}$ & Challenges & In which case? \\
\hline \multirow{6}{*}{ 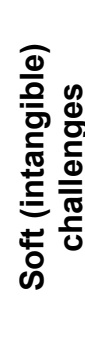 } & $\begin{array}{l}\text { Lack of commitment from the top-management level or } \\
\text { from participants themselves }\end{array}$ & $\begin{array}{c}\mathrm{C} 1, \mathrm{C} 3, \mathrm{C} 6, \mathrm{C} 7, \mathrm{C} 9 \\
\mathrm{C} 11\end{array}$ \\
\hline & $\begin{array}{l}\text { Participants resisted the change "this is how l'have done } \\
\text { it' attitude }\end{array}$ & $\begin{array}{c}\mathrm{C} 1, \mathrm{C} 3, \mathrm{C} 6, \mathrm{C} 7, \mathrm{C} 8 \\
\mathrm{C} 11\end{array}$ \\
\hline & Organisational inertia & $\mathrm{C} 3, \mathbf{C 6}, \mathbf{C 7}, \mathbf{C 8}$ \\
\hline & Lack of Leadership & $\mathrm{C} 1, \mathrm{C} 2, \mathrm{C} 3, \mathrm{C} 9$ \\
\hline & Bad team chemistry & $\mathrm{C} 3, \mathbf{C 9}$ \\
\hline & Cultural issues (e.g. "Commitment and attitude to time") & C4, C5 \\
\hline \multirow{5}{*}{ 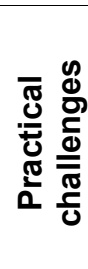 } & $\begin{array}{l}\text { Novelty of LPS to the participants and lack of } \\
\text { understanding of the new system and lean thinking }\end{array}$ & $\mathrm{C} 3, \mathbf{C 6}, \mathbf{C 7}, \mathbf{C 8}, \mathrm{C9}$ \\
\hline & Short term vision & $\mathrm{C} 4, \mathrm{C} 5$ \\
\hline & Human capital (lack of skills and training) & $\mathrm{C} 3, \mathbf{C 8}$ \\
\hline & Lengthy approval procedure by the client & $\mathrm{C} 4, \mathrm{C} 5$ \\
\hline & The language barriers & C10 \\
\hline
\end{tabular}

\section{RESULTS}

\section{LAST PLANNER@ SYSTEM IMPLEMENTATION}

Table 3 is a summary of what has been recorded during the observations and from the first two interviews. 
Table 3: Implementation process of the LPS in Minnevika Bridge project

\begin{tabular}{|c|c|c|}
\hline Phase & Content & Description of the meeting /day \\
\hline \multirow{5}{*}{ 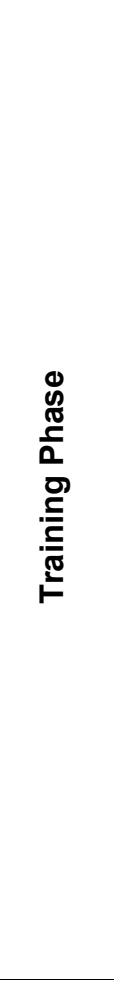 } & $\begin{array}{l}\text { Training } \\
\text { Session }\end{array}$ & $\begin{array}{l}\text { - The Trainers explained the meaning of the LPS and Lean } \\
\text { construction process by carrying out a theoretical explanation and by } \\
\text { using "Villego Simulation" game. - Collaborative planning was } \\
\text { described. }\end{array}$ \\
\hline & Workshop 1 & $\begin{array}{l}\text { - Introduction to the five Lean principles, namely, value, optimisation, } \\
\text { flow, pull and continuous improvement. - Introduction to process } \\
\text { mapping using the pull principle to visually describe the workflow. } \\
\text { - Roles and responsibilities for each member have been defined, and } \\
\text { team rules have been established. }\end{array}$ \\
\hline & Workshop 2 & $\begin{array}{l}\text { - The project team defined the project gates and important } \\
\text { milestones. } \\
\text { - They used the collaborative planning process and the reverse } \\
\text { phase scheduling for developing those plans. }\end{array}$ \\
\hline & Workshop 3 & $\begin{array}{l}\text { - Six-week lookahead plan was executed based on the steps } \\
\text { specified by Ballard et al. ( } 2007 a) \text {, namely, explosion, screening and } \\
\text { Make-ready. }\end{array}$ \\
\hline & $\begin{array}{c}6 \text { PEP } \\
\text { (production } \\
\text { evaluation and } \\
\text { production } \\
\text { planning) } \\
\text { Meetings }\end{array}$ & $\begin{array}{l}\text { - The project team established the weekly work plan (WWP) and } \\
\text { modified the six-week lookahead plan (under the supervision by the } \\
\text { trainers) - lasted for six consecutive weeks. • The trainers used an } \\
\text { action plan and a risk matrix as a way to make tasks ready. - The } \\
\text { team evaluated the weekly performance using Key Performance } \\
\text { Indicators (KPIs), including PPC, milestone completion, and } \\
\text { Variance analysis (by going through the commitments of each party } \\
\text { searching for reasons of failure to learn from mistakes). }\end{array}$ \\
\hline \multirow{2}{*}{ 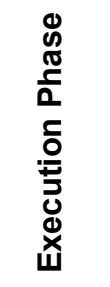 } & $\begin{array}{l}\text { LPS practical } \\
\text { Implementation }\end{array}$ & $\begin{array}{l}\text { - The Trainers handed over the Last Planner } ® \text { System to the project } \\
\text { team and specifically to the LPS Facilitator and the process expert (a } \\
\text { person that supports the Facilitator). } \bullet \text { The Trainers agreed with the } \\
\text { project team to carry out follow-up sessions to make sure that the } \\
\text { implementation process is on the right track. }\end{array}$ \\
\hline & $\begin{array}{l}\text { PEP } \\
\text { Meetings }\end{array}$ & $\begin{array}{l}\text { - The LPS Facilitator controls the system with the help of the process } \\
\text { expert by using the same steps learned in the } 6 \text { PEP meetings. }\end{array}$ \\
\hline
\end{tabular}

\section{LPS IMPLEMENATION CHALLENGES AND THE SUGGESTED MEASURES}

Doubt towards LPS formed a significant challenge in the Training Phase. In contrast, doubts decreased dramatically after entering the Execution Phase. Many of the participants have reaffirmed their support to the LPS thanks to the benefits gained.

During the training sessions, the language formed a great barrier against the implementation process. Gathering almost seven different nationalities, speaking five different languages in the same room could result in some challenges. It was mentioned by one of the site managers that "you cannot take it for granted that everyone understands the same thing when something is said ". Additionally, newcomers started to show up in the PEP meetings, which resulted in some challenges associated with the level of knowledge they had compared to the other participants.

According to results from the interviews and surveys, maintaining participants' commitment to the LPS was considered as the most critical challenge in the Execution Phase due to its huge ramifications on the implementation process. It was clear-cut when the site manager said that "Without the commitment of the participants, it would be very 
hard to take any benefit from the system, it is based on the commitment from all the parties."

The interviews revealed one more critical challenge which emerged during the Execution Phase, namely, Difficulty in understanding the KPIs by some of the participants.

Fear of responsibility when making the commitments (mainly from lower-level management) was observed multiple times during the Training Phase, and it was declared by the participants (through interviews) that it is still a challenge during the Execution Phase.

Table 4 illustrates the critical challenges that occurred through two phases of the implementation of LPS; namely the Training Phase (TPhase) and the Execution Phase (EPhase) and the measures used to overcome these challenges. Those challenges have been recorded with the help of eight months of observations (the researchers observed the training sessions, the three workshops, and all the PEP meetings), six semi-structured interviews, and two surveys.

Table 4: Critical challenges recorded in Minnevika Bridge project

\begin{tabular}{|c|c|c|}
\hline Challenges & $\begin{array}{l}\text { Phase } \\
\text { occurred }\end{array}$ & Measures utilised to overcome the Challenge \\
\hline $\begin{array}{l}\text { 1) Doubt (doubt about the } \\
\text { overall performance and the } \\
\text { benefits behind the LPS) }\end{array}$ & TPhase & $\begin{array}{l}\text { - Sufficient training to the practitioners by showing } \\
\text { the benefits of the system during the training, ask } \\
\text { them to give their feedback to the Trainers for } \\
\text { resolving their doubts and learn by doing. }\end{array}$ \\
\hline 2) Language barriers & TPhase & $\begin{array}{l}\text { - Presentation of the commitments by the Last } \\
\text { planner at the end of the PEP meeting to assure } \\
\text { understanding of what they have committed to. } \\
\text { - Definition of the team rules }\end{array}$ \\
\hline $\begin{array}{l}\text { 3) The non-participation of } \\
\text { the JV partner in the training } \\
\text { sessions and workshops. }\end{array}$ & TPhase & $\begin{array}{l}\text { - They escalated the issue, and changed the } \\
\text { person that should attend the meetings, and } \\
\text { explained in detail the LPS to the newcomer. }\end{array}$ \\
\hline $\begin{array}{l}\text { 4) Newcomers to the PEP } \\
\text { meetings }\end{array}$ & TPhase & $\begin{array}{l}\text { - The Trainers demonstrated the LPS to the } \\
\text { newcomers into detail to reach an equivalent level } \\
\text { of knowledge with other participants. }\end{array}$ \\
\hline $\begin{array}{l}\text { 5) Maintaining participants' } \\
\text { commitment to be part of the } \\
\text { process and to take the } \\
\text { system seriously. }\end{array}$ & EPhase & $\begin{array}{l}\text { - Building up the real trust to the LPS and between } \\
\text { all of the participants (building a positive } \\
\text { environment) by consistently elaborating the } \\
\text { benefits behind the LPS to the different parties. }\end{array}$ \\
\hline $\begin{array}{l}\text { 6) Difficulty in } \\
\text { understanding the KPIs by } \\
\text { participants }\end{array}$ & $\begin{array}{l}\text { TPhase } \\
\text { +EPhase }\end{array}$ & - No measures were taken. \\
\hline $\begin{array}{l}\text { 7) Fear of responsibility } \\
\text { when making the } \\
\text { commitments (mainly from } \\
\text { lower-level management) }\end{array}$ & $\begin{array}{l}\text { TPhase } \\
\text { +EPhase }\end{array}$ & $\begin{array}{l}\text { - Internal agreement/discussion within different } \\
\text { companies about the minimum experience needed } \\
\text { to be in the PEP meetings in order to make reliable } \\
\text { weekly plans. }\end{array}$ \\
\hline $\begin{array}{l}\text { 8) The non-participation of } \\
\text { critical participants due to } \\
\text { circumstances beyond their } \\
\text { control }\end{array}$ & $\begin{array}{l}\text { TPhase } \\
\text { +EPhase }\end{array}$ & $\begin{array}{l}\text { - Request him/her to inform the other participants } \\
\text { about the executed work and the planned work for } \\
\text { the next week (by email for example), or by } \\
\text { sending a delegate who has the responsibility to } \\
\text { make the commitments in the PEP meeting. }\end{array}$ \\
\hline
\end{tabular}

In Table 4, the researchers sorted out the challenge connected to the non-participation of the different participants into two different categories due to the fact that the company used different measures to cope up with each case, but in general, the impact of the non- 
participation of any of the key persons in the meeting had a substantial influence on the meeting. The site manager said "if we are missing one party during the meeting, sometimes we can assume their plan, but we will not do it with the required precision. We cannot do it on behalf of them every time."

\section{OPENNESS AND ATTITUDES TOWARDS LPS}

The two surveys examined openness and attitudes towards LPS during the implementation. The results from the first survey indicated that 8 out of 13 respondents had never heard about LPS before, while 11 out of 13 had not worked with it. Ten of the respondents from the first survey were ready to be part of LPS and learn more about it. In the second survey, the responses were even more positive. 8 out of 8 were motivated to be part of the LPS after understanding its benefits.

\section{PPC RESULTS}

The researchers managed to record the PPC results over a period of eight weeks. The results showed high Percent Plan Complete (PPC), which ranged from $80 \%$ and $100 \%$ (100\% PPC was observed two times over the eight weeks).

\section{DISCUSSION}

\section{LAST Planner@ System ImPlementation PROCESS}

In the beginning, PNC chose to carry out both of the training mechanisms recorded by Ballard et al. (2007b), namely, "classroom" training (the training sessions) and "learning by doing" training (the three workshops and the 6 PEP meetings). The project team implemented the Master phase schedule at the beginning of the project, and overall project duration and important milestones were defined. During the first workshop, they applied "the process mapping method", which has been highlighted by Hamzeh and Bergstrom (2010) as vital for LPS implementation. During the second and third workshops, the trainers presented the phase schedule and the lookahead plan, as suggested by Ballard et al. (2007b). Subsequently, the company executed weekly work plan-meetings, but they gave it the name PEP meetings. The PEP meetings were comprised of all the components of the WWP meetings; including, assessment of PPC, applying the variance analysis, using the root cause analysis method, modification of lookahead plan, and learning from mistakes. The only difference is that they used Pareto charts, instead of "The Five Whys technique" mentioned by Ballard et al. (2007b) for identifying root causes for failure.

Moreover, as a way of continuous improvement, the Facilitator incorporated new tools, for instance, an indicator for measuring the order and safety on-site and an indicator for completed milestones. The Facilitator even incorporated a talk about the logistics onsite in the PEP meetings. Finally, the Trainers suggested follow-up sessions in order to ensure that the participants had understood the process and did not deviate from the drawn path. The high PPC results in Minnevika Bridge project proves a very good beginning.

\section{LPS IMPLEMENTATION CHALLENGES AND THE SUGGESTED MEASURES}

\section{The Training Phase}

According to the literature review, participants' resistance to the system and lack of commitment towards LPS have been challenging for many construction projects, irrespective of the type of the project (e.g. infrastructure projects or other construction 
projects). Whenever there is a change in the management system that involves participants (such as adopting the Last Planner system for the first time in a pilot project), it would be vital that participants accept it. Participants often resist changes. In this case study, resistance to change materialised during the Training Phase. The JV partner did not participate in the training sessions, nor in the workshops. This may be a result of doubt towards LPS. According to the interviews and the two surveys, there are three root causes for the doubt: 1 . The novelty of the system for most of the participants 2 . Troublesome experiences with LPS for some of them from before 3. Broad experience with other systems makes it unnecessary to change. Diminishing those doubts will take some time (depending on the participants). Every participant should be open towards the new system. This happened in the case study, as according to the first survey, more than $80 \%$ of respondents have shown openness towards the system. Once the team was ready to know about the system, sufficient training, building trust towards the system, and building trust towards each other was the responsibility of the trainers. The trust towards the system can gradually increase by continuously working with it and elaborating the benefits. The trust towards each other, especially when the participants are from different companies like in this case study, will be built with the help of long term efforts.

Ballard et al. (2007b) mentioned that the training sessions help to create a better understanding of the system. The lack of training in C3 and C8 identified in the literature review impacted negatively on the participants' understanding. In the Minnevika Bridge project, many participants gave positive feedback about how they benefitted from the training sessions. Finally, regarding "Learning by doing" training, the three workshops and the 6 PEP meetings represented the final step to reduce the doubts before handing the system over to the project. Before that, it was vital to get all the critical participants involved, so the initial representative from the JV partner was substituted by a new representative, who was introduced to the system in detail.

As mentioned in Table 4, the participants started to learn by operating the system under the supervision of the Trainers who trained them, guided them, and showed them the benefits of the system and how to utilise its tools. Subsequently, many of them started to change their minds towards the LPS; and that was quite clear when many newcomers started to show up during the last PEP meeting in the Training Phase. On the other hand, this formed a new challenge as the newcomers were not on the same level of training with other participants. The introduction of new participants, if not handled correctly, could change the atmosphere of the sessions and lead to some members forming a bad image of the system. It is a requirement to elaborate the system into greater detail for them in the beginning until they get up to speed with the others. This is how it was handled on the Minnevika project.

In addition to the previously stated challenges, language formed a significant challenge during the Training Phase, similar to that which occurred in C10. Moreover, Fauchier and Alves (2013) declared that when using LPS, clear commitments (understood by all) should be made, but if the language is a challenge that could be unfeasible. To address this, at the end of the meeting, the Facilitator should make sure that everybody understood what they committed to by presenting those commitments to the other participants in the room. Additionally, the presence of various languages in the same room could lead to a mess. It is therefore advisable to form team rules, such as the one carried out by the project team in this case study, to create a more stable environment, for example by using the rule "all discussions in English. The use of other languages only permitted 
if it is really necessary to explain a difficult topic". This rule seems simple but can have a positive impact on the working environment during the meeting.

\section{The Execution Phase}

After diminishing the doubts and acquiring participants' commitment towards the LPS, the next area of focus is to maintain this commitment. It was mentioned in the findings that "maintaining participants' commitments" was considered as the most critical challenge between all the other challenges during the project phase. The transition from the Training Phase to the new Execution Phase, with the handing over the system to the project team, is termed the transition point by the researchers. After this point, the Execution Phase begins, where the Facilitator and the process expert were held responsible for the implementation process of LPS on the Minnevika Bridge project. In order to maintain the participants' commitment towards the LPS in this phase, trust towards the system and between the participants should remain stable, or even be improved. Fauchier and Alves (2013) detected that the system contributes to building trust between participants by making them more transparent, but this occurs over the long term. The researchers support this point of view, but it is also vital to consider the short time and maintain the level of trust established. This is where the responsibility of the Facilitator arises. The Facilitator should be cautious when using the KPIs, at least in the beginning of the Execution Phase, regardless of the value KPIs add to the system. On the other hand, KPIs can act as a reason for shaming and blaming inside the meeting, and that can result in destroying the established trust between participants, and by extension, towards the LPS. The Facilitator should show the results to the participants as usual, but he/she can be a bit "soft" when dealing with those results. On the Minnevika Bridge project, although they got high PPC, they thought in the same manner. The point was to build trust, and the results were expected to come with time.

"To have a Facilitator with little experience in LPS" was anticipated by the researchers to form a great challenge to the implementation process in Minnevika Bridge project, but it was quite the contrary; The Facilitator was acquainted with Lean thinking and how it can be executed inside organisations, which facilitated her duties inside the project.

\section{The challenges emerged in both phases}

It was confusing for many of the participants to analyse and understand the KPIs, and that was in the same line with what was mentioned in $\mathrm{C} 3, \mathrm{C} 6, \mathrm{C} 7, \mathrm{C} 8, \mathrm{C}$. "Learning by doing" is the solution for this challenge. The point here is that they had not experienced so much of the process yet, and that needs time.

"Fear of responsibility when making the commitments (mainly from lower-level management)" was also recorded as a critical challenge during the implementation. This seems to be conventional due to lack of experience. The point here is to have a minimum level of experience inside the room in order to make reliable promises; the attendance of critical participants (e.g. site managers, supervisors and especially foremen) is always a requirement to have the most reliable commitments. Otherwise, should a critical member not be available, preparation in advance with a representative (e.g. site engineers) should be executed to ensure as many reliable plans as possible are committed to in the PEP meetings. 


\section{CONCLUSIONS AND FUTURE WORK}

By the use of action research, this paper studies implementation of LPS in the Minnevika Bridge project, which will result in Norway's longest railway bridge. In addition, the challenges from implementation and the measures suggested to overcome the challenges, were studied. The study contributes to filling the knowledge gap connected with the lack of research papers examining the implementation of LPS in infrastructure projects.

The study indicated that the implementation had many similarities to the best practice process map mentioned by Ballard et al. (2007a) and Perez and Ghosh (2018). Infrastructure projects and other construction projects tend to meet similar challenges in the Training Phase when adopting the LPS for the first time, despite their different characteristics. These challenges were associated with behavioural aspects of participants, namely the resistance to change and participants' commitments towards the new system. Doubts were essential root causes for these aspects. Following best practice for LPS implementation is a requirement for gaining significant results, but diminishing these doubts is also necessary. Building trust towards the LPS and towards each other is a measure for overcoming these doubts. This can be achieved with three steps; sufficient training (Trainers' responsibility), openness towards the system (participants' responsibility), building trust to maintain participants' commitment towards the system (Facilitator's responsibility).

Finally, regarding the uniqueness of the project, the researchers managed to find two new challenges from Minnevika Bridge project that seem not to have been identified in the literature, namely, fear of responsibility when making the commitments, newcomers to the PEP meetings.

The literature review conducted did not reveal evidence of any research being done on the application of follow-up sessions by Trainers during the implementation of LPS and how these sessions can influence the process. It is, therefore recommended by the researchers as a topic to be further studied.

\section{ACKNOWLEDGMENT}

The authors are grateful to the multiple facilitations that both PNC Norge AS and NTNU Norwegian University of Science and technology offer for the successful completion of this research. Thank you to all the case study participants for their cooperation.

\section{REFERENCES}

Ansah, R. H., Sorooshian, S., Mustafa, S. B., and Duvvuru, G. 2016. "Lean construction tools". Proceedings of the 2016 International Conference on Industrial Engineering and Operations Management Detroit, Michigan, USA.

Ansell, M., Holmes, M., Evans, R., Pasquire, C., and Price, A. 2007. "Lean construction trial on a highways maintenance project. Proceedings of the 15th conference of the International Group for Lean Construction, East Lansing, United States.

Ballard, G., Hamzeh, F., and Tommelein, I. 2007a. "The Last Planner Production Workbook-Improving Reliability in Planning and Workflow". Lean Construction Institute, San Francisco, California, USA, pp. 81.

Ballard, G., and Howell, G. 2003. "Lean project management". Journal of Building Research and Information, 31(2), pp. 119-133. doi:10.1080/09613210301997

Ballard, G., Kim, Y. W., Jang, J. and Liu, M. 2007b. "Road Map for Lean Implementation at the Project Level". The Construction Industry Institute, The University of Texas at Austin, Texas, USA, pp 426. 
Barbosa, F., Woetzel, J., Mischke, J., Ribeirinho, M. J., Sridhar, M., Parsons, M., Bertram, M., and Brown, S. 2017. Reinventing construction: A route to higher productivity. New York, NY: McKinsey and Company.

Cerveró-Romero, F., Napolitano, P., Reyes, E., and Teran, L. 2013. "Last Planner

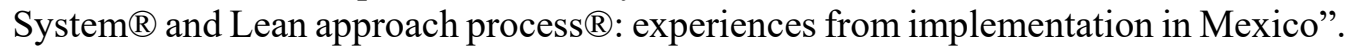
Proceeding of the 21st Annual Conference of the International Group for Lean Construction, Fortaleza, Brazil.

Fauchier, D., and Alves, T. d. C. L. 2013. "Last Planner ${ }^{\circledR}$ System Is the Gateway to Lean Behaviors". Proceeding of the 21th Annual Conference of the International Group for Lean Construction, Fortaleza, Brazil.

Fernandez-Solis, J., Porwal, V., Lavy, S., Shafaat, A., Rybkowski, Z., Son, K., and Lagoo, N. 2013. "Survey of Motivations, Benefits, and Implementation Challenges of Last Planner System Users". Journal of Construction Engineering and Management, 139, 354-360. doi:10.1061/(ASCE)CO.1943-7862.0000606.

Hamzeh, F. 2009. Improving construction workflow-The role of production planning and control. PhD Dissertation, University of California, Berkeley.

Hamzeh, F., and Bergstrom, E. 2010. "The lean transformation: a framework for successful implementation of the last PlannerTM system in construction". International Proceedings of the 46th Annual Conference. Associated Schools of Construction. Wentworth Institute of Technology, Boston.

Howell, G., and Ballard, G. 1998. "Implementing lean construction: understanding and action". Proc. 6 th Ann. Conf. Intl. Group for Lean Constr.

Jang, J. W., Kim, Y.-W., Park, C. J., and Jang, W. S. 2007. "Importance of partners in a challenging lean journey". Proc., 15th Annual Conf. of the Int. Group for Lean Construction (IGLC-15), Michigan.

Järvinen, P. 2007. "Action research is similar to design science. Quality and Quantity", 41(1), pp. 37-54.

Kim, Y.-W., Park, C., and Ballard, G. 2007. "A case study on rebar supply chain management by GS E\&C". Proc., 15th Annual Conf. of the Int. Group for Lean Construction (IGLC-15). Salford, U.K.

Koskela, L. (1992). Application of the new production philosophy to construction (Vol. 72): Stanford university Stanford, CA.

Kotter, J. P. 2012. Leading change. Boston, Mass, Harvard business press.

Liker, J. K. 2004. The Toyota Way: 14 Management Principles from the World's Greatest Manufacturer. New York: McGraw-Hill.

Lim, C.-W., Yu, J.-H., and Kim, C.-D. 2006. Implementing PPC in Korea's Construction Industry. 14th Annual Conference of the International Group for Lean Construction, Santiago, Chile.

Mossman, A. 2014. Collaborative Planning: 5+ 1 crucial and Collaborative Conversations for Predictable Design and Construction Delivery. In: The Change Business Ltd.< http://bit. ly/CPS-5cc>(20May15).

O. Alsehaimi, A., Tzortzopoulos Fazenda, P., and Koskela, L. 2014. "Improving construction management practice with the Last Planner System: a case study". Engineering, Construction and Architectural Management, 21(1), 51-64.

Perez, A., and Ghosh, S. 2018. "Barriers faced by new-adopter of Last Planner System ${ }^{\circledR}$ : a case study". Engineering, Construction and Architectural Management, 25 (9), pp. $1110-1126$. 